\title{
Assessment of Residents' Level of Neighbourhood Satisfaction in Violence-Induced Segregated Urban Environments
}

\author{
*Rasheed Osuolale Oladosu \\ URP Department, Abubakar Tafawa Balewa University, Bauchi, Nigeria \\ Siyaka AbdulRahman Arudi \\ URP Department, Abubakar Tafawa Balewa University, Bauchi, Nigeria \\ Yusuf AbdulWaheed Adeiza \\ URP Department, Abubakar Tafawa Balewa University, Bauchi, Nigeria
}

\begin{abstract}
Urban violence has resulted into segregation of urban dwellers along neighbourhood divides in many cities of the world. It is well documented that neighbourhood satisfaction is a vibrant contributor to the overall wellbeing of urban dwellers; yet, investigative research on how satisfied are residents in such violence-induced segregated urban environments- a neighbourhood scenario where different ethnic, religious or ethno-religious groups previously co-existed but later parted as a result of inter-group violence, seems not to have been given sufficient attention as a specific matter of concern in neighbourhood studies. Exploring the attributes of the physical and social environment as well as neighbourhood facilities and public utilities, this study examined the level of neighbourhood satisfaction in the segregated Jos city of Nigeria, through a measure of central tendency and spread, employing SPSS-22. The study discovered that residents experienced low degree of satisfaction in both homogenous and mixed neighbourhoods identified in the city. Analysis however revealed significant differences between the two types of neighbourhood in terms of elements examined in relation to the three key attributes employed for the examination.
\end{abstract}

Keywords: neighbourhood satisfaction, violence-induced, segregated urban environment, homogenous neighbourhood, mixed neighbourhood

DOI: $10.7176 / \mathrm{CER} / 12-6-07$

Publication date:June $30^{\text {th }} 2020$

\section{Introduction}

Cities are famous for their magnetic attraction to people for reasons of their economic and education prosperities, and as well access to facilities, utilities and services. They equally serve as centres of exposure and social contacts. This has often resulted into the development of multiethnic or pluralistic ethnoreligious cities which are found on different parts of the globe. Complexities created by this pluralistic array of ethnic, religious or ethnoreligious and/or socio-cultural mix of the inhabitants has widely manifested in various social challenges that urban managers have continued to contend with. One of such identified challenges by researchers, is urban violence or social conflict (Hur et al., 2015; Kasara, 2015; Rakodi, 2012). According to Bhavnani et al. (2014), multiple reports of outbreak of violence across many multiethnic cities of the world is a clear indicator of the fragility of the existing relationship among resident groups in these cities. De Vita et al. (2016) also observe that contemporary cities are faced with the challenge of social conflict as a result of the presence of different groups divided along cultural, religious or ethnic divides.

A major resultant consequence of the violence in recent time, is neighbourhood (Gambo and Omirin, 2012). There have been several such cases of intra and inter-ethnoreligious violence in many Nigerian cities most especially in the northern part of the country. These violence have either resulted into social segregation of the cities or deepening the segregation pattern created during the colonial administration but had significantly faded off over time.

Despite the above theoretical notes that some cities of the world are segregated on the basis of urban violence, it appears scholarship research has not been much focused on the aftermath events of this violence-driven type of segregation. One of such areas that its knowledge is very important due its contributions to the wellbeing, quality of life and overall life satisfaction (Misun and Hazel, 2008; Oktay and Marans, 2011; Porio, 2015) but is yet to be given the desired attention as a specific urban concern, are studies evaluating the level of neighbourhood satisfaction of residents in such urban environments where residents initially shared common neighbourhoods and the same socio-cultural environment but later fell off and reside in neighbourhoods that are homogenously bound by common characteristics usually ethnicity or religion (Aliyu et al., 2012; De Vita et al., 2016). The interest of this research is to therefore as a result of these observations and reports, examine this missing gap in neighbourhood studies using Jos in Nigeria as the study setting.

Jagun et al. (1990) investigated the residential satisfaction of the urban Blacks in the United States (US) with 
a view to finding out how racial segregation impacted their satisfaction with the physical environment and socioeconomic factors. Other researchers such as Swaroop and Krysan (2011) examined the racial proxy hypothesis to determine in which neighbourhood's type did each racial group derive higher level of neighbourhood satisfaction and found that the Whites prefer neighbourhoods of the Whites' dominance (homogenous neighbourhoods) while the Blacks prefer neighbourhoods with a sizable proportion of the Whites and Blacks (mixed neighbourhoods). However, these studies cannot explain neighbourhood satisfaction in violence-induced segregated urban environments due to its peculiar characteristic of co-existence before parting as a result of violence. A situation Bhavnani et al. (2014) refers to as living together but not living with each other in Belfast and Aliyu et al. (2015) described as two cities in a single town in Jos.

Between 2001 and 2010, it was reported that several houses were burnt with several lives and large volume of property loss in Jos city due to urban violence (Aliyu et al., 2015; Krause, 2011). The city became polarized along ethnic and religious divides with Muslims converging in neighbourhoods mostly found around the centre of the city, subdividing plots and raising heights of existing structures, thereby further increasing the density of the already overcrowded centralized residential neighbourhoods (Dung-Gwom and Rikko, 2009). Studies further stated that the Christians on the other hand, massively moved to such neighbourhoods where they felt they were save, some in the city area and others away in the suburbs. The concept of 'no-go-area', that is, restricted interneighbourhood movements, emerged (Dung-Gwom and Rikko, 2009; Krause, 2011). In essence, there was a complete alteration of the neighbourhood pattern of the city resulting in homogenous neighbourhoods' development (Aliyu et al., 2012, 2015; Krause, 2011). Residents are expectedly not satisfied with the neighbourhood environments under this type of residential circumstance since freedom of choice which has been suggested as a strong determinant of neighbourhood satisfaction (Bischoff and Reardon, 2013; Hamersma et al., 2014; Permentier, 2011), is outstandingly lost in the city.

\subsection{Data and Method}

This study is a section of a larger research conducted on neighbourhood satisfaction of residents in violenceinduced segregated urban Jos, Nigeria. The city became segregated along ethno-religious lines as a result of series of inter-ethnoreligious violence, most intensively between 2001-2010. A follow-up explanatory sequential mixed method was employed for the study. A total of 115,142 households projected for the study area based on an initial projection at an annual average growth rate of 2.7 by the National Population Commission, was the target population from which 400 samples was required based on the equation of Bartlett et al., 2001 (equation 1). However, in consideration of the negative attitude of some people to participation in survey research as reported in previous studies such as Ibem and Aduwo (2013), the required sample was increased by $20 \%$, thereby increasing the administered questionnaires to 480. The sampling frame was adapted with permission from a previous study, Krause (2011). The study which was a working paper prepared for Geneva Declaration on the violence in Jos, identified 18 neighbourhoods in the city subdivided into three types: Muslim, Christian and mixed. Dung-Gwom and Rikko (2009) and field observations in the process of conducting this study, however noted that each of the first two types, is aligned with a dominant ethnic group. Hence, sample for the study was selected aiming to generate geographical and ethnoreligious representations, using proportional quota sampling technique.

$$
\mathrm{n}=\frac{\mathrm{N}}{1+\mathrm{N}(\mathrm{e})^{2}}
$$

with $\mathrm{n}=$ sample size, $\mathrm{N}=$ population of study, and $\mathrm{e}=$ margin of error $(\alpha=0.05)$

The initial draft of the questionnaire was pretested with 10 staff of a high school in Jos. Basically, wordings in few of the questions were found to require simplification after their responses. The outcome of the pre-test also informed the need to delete two questions due to a high percentage of the respondents who provided open-ended and unanalysable answers to them. Following the adjustment of the instrument, it was piloted on a sample of 45 residents from three different neighbourhoods. The responses were analysed using SPSS-22 and the results indicated that respondents now had a better comprehension of the questions.

A total of $454(94.6 \%)$ of the 480 administered questionnaires were successfully retrieved but only 289 $(63.7 \%)$ of these were valid and used for further analysis. The remaining were observed to be inadequately completed or completed without the much needed consciousness of its essence for research in mind. The valid response rate was however, well above 52.7\% average reported by Baruch and Holtom (2008) in their analysis of 490 various researches that collected their data using questionnaire instruments. Studies such as Ibem et al. (2017) also got valid response rate of about $60 \%$ in their study of neighbourhood satisfaction in public housing in Nigeria.

From the larger study, the section of the questionnaire instrument used for this study was made up of 50 items sub-divided into three parameters, used in measuring residents' satisfaction with the attributes of their physical environment, social environment and neighbourhood facilities and public utilities. A 5-point Likert scale: 1 Strongly not satisfied, 2 - Not satisfied, 3 - Fairly satisfied, 4 - Satisfied, and 5 - Strongly satisfied, was used to obtain the level of satisfaction/dissatisfaction with different aspects of these parameters. The researchers examined the internal consistency (reliability) of the scale by calculating the Cronbach's Alpha of each parameter. The results obtained are contained in Table 1 below. On the basis of 0.7 recommended as a reliable co-efficient alpha by 
Pallant (2011), the instrument was considered fit for the assessment of the level of neighbourhood satisfaction in a violence-driven segregated urban environment. Cross-tabulations were conducted to examine possible contradictions among the various attributes of the socio-demographic characteristics of the respondents, but were all found to be valid.

Table 1: Reliability Analysis ( $\mathrm{n}=289)$

\begin{tabular}{|l|l|l|}
\hline Construct & Number of items & Cronbach Alpha \\
\hline Neighbourhood physical environment attributes (NPEA) & 15 & 0.775 \\
\hline Neighbourhood social environment attributes (NSEA) & 20 & 0.844 \\
\hline Neighbourhood facilities and public utilities (NFPU) & 15 & 0.795 \\
\hline
\end{tabular}

Due to the nature of the study, analysis of the data was done using descriptive statistics of a measure of central tendency (mean attribute score) and spread (standard deviation). The findings are expressed in index of each parameter and discussed in terms of the mean attribute satisfaction score (MASS) obtained for each of the variables as expressed by the respondents from both homogenous and mixed neighbourhoods. Rather than discussing individual items on the list of the variables measuring each parameter, and considering relationships among them based on previous studies, themes were created for the purpose of cohesive discussions and comparisons between homogenous and mixed neighbourhoods.

Having analysed the quantitative data collected from household heads across the 18 neighbourhoods and observed the direction of interpretations of the results, the need for further information and justification of some aspects of the results became obvious. Hence, interview was conducted with 10 purposively sampled stakeholders whose official services have direct link with the residents. The drafted interview questions were validated by the serving Head of Department of Urban and Regional Planning, University of Jos and his observations were used to review the instrument accordingly.

The qualitative sample was framed as contained in Table 2. Two stakeholders were selected from five institutions/organizations. They all possessed three aforestated qualities of age, years of residence in Jos and relationships with the research problem, in line with the recommendations of Tongco (2007).

Table 1: Sample Selection for the Qualitative Data

\begin{tabular}{|l|l|l|}
\hline Organization/Institution & Number sampled & Respondent's code \\
\hline Jos Metropolitan Development Board (JMDB) & 2 & S1, S2 \\
\hline Jos North Local Government (JNLG) & 2 & S3, S4 \\
\hline Plateau Traditional Council (PTC) & 2 & S5, S6 \\
\hline Non-governmental organization NGO & 2 & S7, S8 \\
\hline Religious Institution (RI) & 2 & S9, S10 \\
\hline & 10 & \\
\hline
\end{tabular}

$\mathrm{S}=$ Stakeholder

Content Analysis was employed for analysis of the qualitative data. Having transcribed the recorded interviews, codes were affixed to suitable sections of the transcripts. The codes were then transformed into categorical themes and sub-themes, and the latter used to identify nodes. Relationships and intersections were identified among the nodes and findings were then interpreted, relating them to the previous results obtained from the quantitative analysis. Direct statements quoted from the respondents, in line with the identified nodes, were used to support the earlier discussions that were made on the basis of the quantitative outcomes, in order to gain further insights into the outcome of the research and equally validate the discussion of findings in appropriate sections of the study.

\subsection{Results and Discussion}

\subsection{Respondents' Demographic Profile}

Consistent with some studies in many developing nations (Ibem and Aduwo, 2013; Mohit et al., 2010), only 29.4\% of the sample were females while a larger proportion $(70.6 \%)$ of the respondents were males. This appears to be in tune with the culture of Jos, the study area like most other parts of Nigeria where males are generally the household heads as was similarly observed by Chado (2017) in his study in another Nigerian city. In the age distribution of the participants, most of the respondents (72.6\%) are in the active and working age range of 31-60 years. Buys and Miller (2012) similarly discovered that $79 \%$ of his sample in Brisbane fell in this age bracket. Those below 31 years made up $12.3 \%$ while others who were above 60 years made up $15.1 \%$ of the total respondents. This influences the results obtained in respect of the next two variables in the Table 2 , where $79.2 \%$ were married with about $87 \%$ having children below 18 years.

Jos city is made up several ethnic groups put at over 50 (Ostien, 2009) with four dominant ones. Among these, the Hausa ethnic group is dominant representing 39.4\% of the total respondents while the natives which is next constitutes $27.2 \%$. The other two groups, Yoruba and Igbo are respectively made up of $14.5 \%$ and $10.4 \%$ of the total respondents. All other groups collapsed as other minorities constitutes $8.0 \%$. The respondents are largely Muslims with a proportion of $54.7 \%$ while the Christians were made up of $40.1 \%$ of the respondents in the survey. 
Those belonging to other religions such as traditional worshippers made up $3.5 \%$ while $1.7 \%$ claimed not belonging to any religious group. The larger population of the Muslims as represented by the sample is due to the fact that virtually the entire Hausa group are Muslims as earlier noted while a sizable proportion of other ethnic groups also belong to the Muslim religious group. This was however not expected to have impact on the findings of the research since both the Muslim and Christian neighbourhoods are jointly analysed as homogenous neighbourhoods.

In terms of education, the result shows that the majority, about $69 \%$ attained degree and higher education. This declines sharply from the $95.6 \%$ obtained by Ibem et al. (2017). The difference was believed to be due to the conduct of their study in formal public housing neighbourhoods unlike this research that collected data from household heads over the open neighbourhoods. The relatively higher proportion of higher education holder in this research's data is equally in dissonance with studies in other developing countries such as Mohit et al. (2010) in Malaysia and $\mathrm{Li}$ and $\mathrm{Wu}(2013)$ in China where less than $40 \%$ of their respondents attained higher education. This presumably is due to cultural context. The minimum wage in Nigeria is N18, 000.00. About $51 \%$ of the respondents were low income earners earning N40, 000.00 and below; about $40 \%$ fell in the middle income cadre while only about $10 \%$ were high income earners. The observed high proportion of low income earners in the data despite the large number of higher education holders was presumed to result from almost half of the respondents working in the private sector since there is no salary regulation for the private sector in the country.

A slightly above $50 \%$ of the respondents own their houses while about $42 \%$ are renters with $6.8 \%$ having other form of tenureship. The large percentage of renters might have resulted as part of the long term effects of the internal migrations that occurred due to residential segregation that occurred in the city. The length of respondents' stay (years) in neighbourhoods shows that $63.0 \%$ of the respondents had resided in their current neighbourhoods within a period of twenty years and below. 23.9\% had stayed for 21-30 years while only 13.1\% had stayed longer. This distribution was not expected in a city that had existed for over a century (Dung-Gwom and Rikko, 2009). It appears to be as a result of the violence and the progressively resultant residential segregation which according to HRW, 2001; Krause, 2011; and Ostien, 2009, commenced in 2001.

Table 2: Socio-demographic Attributes of Respondents $(\mathrm{n}=289)$

\begin{tabular}{|c|c|c|c|}
\hline Attribute & Variable & $\%$ & Cumulative $\%$ \\
\hline \multirow[t]{2}{*}{ Gender } & Male & 70.6 & 70.6 \\
\hline & Female & 29.4 & 100.0 \\
\hline \multirow[t]{4}{*}{ Age (Years) } & $18-30$ & 12.3 & 12.3 \\
\hline & $31-45$ & 50.4 & 62.7 \\
\hline & $46-60$ & 22.2 & 84.9 \\
\hline & $61+$ & 15.1 & 100.0 \\
\hline \multirow[t]{4}{*}{ Marital status } & Single & 6.4 & 6.4 \\
\hline & Married & 79.2 & 85.6 \\
\hline & Divorced & 7.4 & 93.0 \\
\hline & Widow & 7.0 & 100.0 \\
\hline \multirow[t]{5}{*}{ Ethnic group } & Natives & 28.7 & 28.7 \\
\hline & Hausa & 39.4 & 68.1 \\
\hline & Yoruba & 13.5 & 81.6 \\
\hline & Igbo & 10.4 & 92.0 \\
\hline & Others & 8.0 & 100.0 \\
\hline \multirow[t]{4}{*}{ Religion } & Muslims & 54.7 & 54.7 \\
\hline & Christians & 40.1 & 94.8 \\
\hline & Others & 3.5 & 98.3 \\
\hline & None & 1.7 & 100.0 \\
\hline \multirow[t]{4}{*}{ Highest education } & $1^{\text {st }}$ degree $\&$ above & 69.3 & 69.3 \\
\hline & Secondary & 15.4 & 84.7 \\
\hline & Others & 14.2 & 98.9 \\
\hline & None & 1.1 & 100.0 \\
\hline \multirow[t]{3}{*}{ Employment status } & Public sector employed & 48.4 & 48.4 \\
\hline & Private sector employed & 42.7 & 91.1 \\
\hline & Unemployed & 8.9 & 100.0 \\
\hline \multirow[t]{3}{*}{ Income level ( $¥)$} & Low $(40,000 \&$ below $)$ & 51.3 & 51.3 \\
\hline & Medium $(40,001-120,000$ & 38.6 & 89.9 \\
\hline & Upper (120,001 \& above) & 10.1 & 100.0 \\
\hline
\end{tabular}




\begin{tabular}{|c|c|c|c|}
\hline Attribute & Variable & $\%$ & Cumulative \% \\
\hline \multirow[t]{3}{*}{ Housing tenure } & Owner-occupier & 50.9 & 50.9 \\
\hline & Renters & 42.3 & 93.2 \\
\hline & Others & 6.8 & 100.0 \\
\hline \multirow{5}{*}{$\begin{array}{l}\text { Children }<18 \text { in } \\
\text { Household }\end{array}$} & $7 \&$ above & 21.3 & 21.3 \\
\hline & $5-6$ & 28.4 & 49.7 \\
\hline & $3-4$ & 16.0 & 65.7 \\
\hline & $1-2$ & 21.2 & 86.9 \\
\hline & None & 13.1 & 100.0 \\
\hline \multirow{4}{*}{$\begin{array}{l}\text { Duration of stay in } \\
\text { neighbourhood (Years) }\end{array}$} & $1-10$ & 30.1 & 30.1 \\
\hline & $11-20$ & 32.9 & 63.0 \\
\hline & $21-30$ & 23.9 & 86.9 \\
\hline & $>30$ & 13.1 & 100.0 \\
\hline
\end{tabular}

$* \$ 1=\mathrm{N} 365$ as at March, 2020

\subsection{Residents' Satisfaction with the Attributes of the Neighbourhood Environment}

Overall mean neighbourhood satisfaction index (MNSI) of 3.1 and 2.8 were respectively obtained for homogenous and mixed neighbourhoods from participants' responses to 50 neighbourhood attributes questions sub-sectioned into three parameters. This indicated that inhabitants of both homogenous and mixed neighbourhoods in the segregated Jos generally have low satisfaction with their current neighbourhood environment. This was also reflected in the MASS of most of the individual attributes that measure each parameter.

This initial finding was supported by most of the interviewees who reiterated that people could not be well satisfied under the current segregation status.

Interviewee S6 for instance said:

... They can't have complete satisfaction because we depend on one another, because if for example, others are traders, others are workers, there are people here who are cattle rearers, there are farmers, and so on. So, we depend on one another for sustainable living but once we have segregated measure, certainly, one, the economy of the state will be affected, people will not trust one another. That is not good for Jos, it sets us back and make us to be suspicious. We are supposed to be groups living together. Neighbourhood satisfaction we are deriving from the segregation is just because of the security. Therefore, we may need to live by it since that is giving us peace.

Interviewee S10 unequivocally said:

(Interviewee S6)

Well, nobody in his right sense will be fully satisfied under this condition. I believe if you gather eggs in one side, you gather may be chicken in one side and you gather geese in the other side, the mixture is not there. And therefore the experiences are not there. Am really afraid for the upcoming generations. Let me just say this, like my son knows nothing about the Islamic religion out of the separation and I believe a friend in a Muslim environment, his son will not know anything about the Christian religion too. Notwithstanding, the situation has come and may have to remain for now.

There were however wide variations in the degree of dis(satisfaction) expressed by the respondents not only between the parameters but among the variable items that measured each of the parameters.

3.2.1 Residents' Satisfaction with the Neighbourhood Physical Environment

Respondents expressed their level of satisfaction by responding to 15 items of the neighbourhood physical environment as contained in Table 3. The results showed that residents of Jos, both in homogenous and mixed neighbourhoods, were mostly not satisfied with their neighbourhood physical environment's attributes.

Mean neighbourhood physical environment satisfaction index (MNPESI) of 2.58 and 2.82 were respectively obtained for homogenous and mixed neighbourhoods, indicating residents in both types of neighbourhoods were not satisfied with the physical environment of their respective neighbourhoods in the segregated city. Infact, this reflected in the mean scores of all the attributes which generally were below 4 (satisfied). Although both were not well satisfied, residents in the homogenous neighbourhoods however indicated a lower degree of satisfaction with this parameter than their counterparts in the mixed neighbourhoods. This appears to be as a result of the violenceinduced segregation experience of the residents. 
Table 3: Respondents' satisfaction with the neighbourhood physical environment attributes

\begin{tabular}{|l|l|l|l|}
\hline Item & Attributes & \multicolumn{2}{|c|}{ MAS (SD) } \\
\cline { 3 - 4 } & & HN & MN \\
\hline 1 & Cleanliness of the neighbourhood environment & $3.39(1.084)$ & $2.99(1.028)$ \\
\hline 2 & Solid waste collection method(s) & $3.45(1.001)$ & $2.43(1.032)$ \\
\hline 3 & Aesthetic appearance of the neighbourhood & $2.93(1.079)$ & $3.29(1.036)$ \\
\hline 4 & General attractiveness of the neighbourhood & $2.14(1.031)$ & $3.35(1.024)$ \\
\hline 5 & Illumination of the neighbourhood at night & $2.57(1.132)$ & $1.46(1.207)$ \\
\hline 6 & Availability of open spaces & $1.80(1.143)$ & $2.97(1.162)$ \\
\hline 7 & Land use arrangement in the neighbourhood & $1.93(1.093)$ & $3.21(1.092)$ \\
\hline 8 & Road network within the neighbourhood & $2.85(1.108)$ & $2.24(1.178)$ \\
\hline 9 & Condition of access roads in the neighbourhood & $1.64(1.107)$ & $3.70(1.393)$ \\
\hline 10 & Provision of pedestrian walkway & $1.73(1.157)$ & $2.82(1.106)$ \\
\hline 11 & Traffic congestion on the roads within the neighbourhood & $2.32(1.003)$ & $3.10(1.190)$ \\
\hline 12 & Distance from neighbourhood to the city centre & $3.41(1.052)$ & $2.25(1.192)$ \\
\hline 13 & Distance of neighbourhood to work place & $3.31(1.082)$ & $2.15(1.022)$ \\
\hline 14 & Physical condition of houses in the surrounding area & $2.15(1.123)$ & $3.19(1.065)$ \\
\hline 15 & Density of housing in the neighbourhood & $3.16(1.071)$ & $3.22(0.962)$ \\
\hline MNPESI & $\mathbf{2 . 5 8}$ & $\mathbf{2 . 8 2}$ \\
\hline
\end{tabular}

HN- Homogenous neighbourhood, MN - Mixed neighbourhood, SD- Standard deviation

In terms of attributes that relate to sanitations and physical attractiveness of the neighbourhoods, residents in homogenous neighbourhoods expressed a bit higher satisfaction with cleanliness, solid waste collection method and illumination at night compared to the mixed neighbourhoods. The mixed neighbourhoods on the other hand, were more satisfied with aesthetic appearance and general attractiveness of their neighbourhood environments than the homogenous neighbourhoods. These findings might not be dissociated from the fact that such services like waste collection which also aids cleanliness of the environment had been a longstanding programme of the local government in the city area where many of the homogenous neighbourhoods are located compared to most of the mixed neighbourhoods that are away from the centre of the city where provision is hardly made for waste collection. This explains why the homogenous neighbourhoods were equally more satisfied with illumination at night than the mixed neighbourhoods because the city centre is more lit than the other areas of the city. However, possibly due to less congestion and more number of modern houses in the mixed neighbourhoods, they tend to be more satisfied with the aesthetic and general appearance of their neighbourhoods than their counterparts in the homogenous neighbourhoods. A reflection of this also is the dissatisfaction of the respondents in the homogenous neighbourhoods with physical condition of buildings in the surrounding areas compared to those in the mixed neighbourhoods who were fairly satisfied. It perhaps also relates to the general older nature of the buildings in the central area of the city where a larger part of the homogenous neighbourhoods (mostly Muslim neighbourhoods) are found as reported by Dung-Gwom and Rikko (2009). This finding is supported by the broken window theory which laid emphasis on the positive association between upkeep and cleanliness and neighbourhood satisfaction. Higher satisfaction of the mixed neighbourhoods with open spaces and landuse than the homogenous neighbourhoods seems to be due to landuse conversion which is worse in the city area as a result of the segregation because as most of the interviewees noted, residents had to equally relocate their businesses to neighbourhoods they believed were safe for them. While the open spaces have been fragmented for residential developments in the city area due to congestion (Dung-Gwom and Rikko, 2009), they were fairly found in sizable numbers in the suburbs and intermediate areas where many mixed neighbourhoods are located.

Interviewee $\mathrm{S} 1$ asked rhetorically:

Open spaces? Where will you get open space in the town here when people are even scouting for land to build houses. If it was before, it is possible but now, it is not. May be those living in the other areas like the outskirt of the town may have some open spaces but not here in the town.

(Interviewee $\mathrm{S} 1$ )

On issues relating to road network, traffic and movement, residents in mixed neighbourhoods were more satisfied with the condition of access roads and provision of pedestrian walkways which were noted to be in better conditions in the suburbs where mixed neighbourhoods are mostly found. Interviewee S7 gave a clue on this:

... Another effect is that some people have been marginalized. If you see roads in some communities where there are no cars you will be astonished, when there are areas that are well developed and you have not gone to develop the roads there and they are paying the same tax to the state government.

(Interviewee S7)

Respondents from homogenous neighbourhoods were however more satisfied with distance covered to their places of work and city centre than those in mixed neighbourhoods. This was expected as it was obvious that most 
residents in the former were closer to the city areas than the latter and as such distances covered to these places which might equally reflect on the economic cost of accessing them, determined their level of satisfaction with them.

In line with the findings of the previous research, findings in respect of the NPEA appear to have been influenced by the socio-economic situations of residents in the segregated environment. For instance, age has been found to influence neighbourhood satisfaction; younger residents tend to be less satisfied with their neighbourhood physical environment than the elderly (Adewale et al., 2015; Buys and Miller, 2012; Chapman and Lombard, 2006). Hence, the concentration of most of the respondents between the ages of $18-45$ is believed to have contributed to the gross low satisfaction expressed in respect of the physical environment attributes irrespective of the type of neighbourhood. About $90 \%$ of the respondents in this study were equally low and medium income earners and as Lee et al. (2016) found in their research, people in these categories tend to be less satisfied with their neighbourhoods compared to the higher income earners. This is similar to the result obtained in the earlier study of Parkes et al. (2002) in the UK.

3.2.2 Residents' Satisfaction with Neighbourhood Social Environment

Twenty attributes were used in investigating residents' satisfaction with the neighbourhood social environment. Samples from the homogenous and mixed neighbourhoods respectively had a mean neighbourhood social environment satisfaction index (MNSESI) of 3.58 and 2.99 (Table 4). This simply translates that residents in homogenous neighbourhoods were satisfied with their neighbourhood social environment while those residing in mixed neighbourhoods expressed fair satisfaction level with this parameter.

Jos city as discussed in chapter three has been widely reported to be segregated along ethnoreligious divides. While 11 of the eighteen neighbourhoods in the city have been designated and reportedly occupied by residents of homogenous ethnoreligious culture, the seven others which succeeded in preventing the spread of violence, the causative agent of the segregation, remained mixed in a manner similar to the past experience of the entire neighbourhoods in the city. A reflection of these could be perceived from the neighbourhood satisfaction level expressed by the respondents of this research. From the list of twenty (20) attributes employed to examine the satisfaction of the residents with their neighbourhood social environment, residents in homogenous neighbourhoods had higher satisfaction level in thirteen (13) while the mixed neighbourhoods experienced higher satisfaction than the homogenous in the other seven (7).

Table 4: Respondents' satisfaction with the neighbourhood social environment attributes

\begin{tabular}{|l|l|l|l|}
\hline Item & Attributes & \multicolumn{2}{|c|}{ MAS (SD) } \\
\cline { 3 - 4 } & & HN & MN \\
\hline 1 & Ethnoreligious composition of residents in the neighbourhood & $4.15(1.251)$ & $3.03(1.335)$ \\
\hline 2 & Religious practice(s) of members of the neighbourhood & $4.65(1.049)$ & $3.25(0.830)$ \\
\hline 3 & Proximity to family and relatives & $4.521 .088)$ & $2.13(1.095)$ \\
\hline 4 & Contact with friends & $4.12(0.988)$ & $3.16(1.022)$ \\
\hline 5 & Contact with members of ethnic group & $3.70(1.052)$ & $2.75(1.026)$ \\
\hline 6 & Contact with members of other ethnic groups & $2.05(1.122)$ & $3.57(1.112)$ \\
\hline 7 & Interaction among members of the neighbourhood & $4.48(1.065)$ & $3.18(0.975)$ \\
\hline 8 & Level of co-operation among members of the neighbourhood & $4.03(1.061)$ & $2.87(0.932)$ \\
\hline 9 & Trust among members of the neighbourhood & $4.83(1.061)$ & $2.27(0.963)$ \\
\hline 10 & Participation in neighbourhood social activities & $3.43(1.035)$ & $3.68(0.836)$ \\
\hline 11 & Quality of social activities in the neighbourhood & $1.84(1.063)$ & $2.85(1.163)$ \\
\hline 12 & Liveliness of the neighbourhood & $3.17(1.106)$ & $3.88(1.163)$ \\
\hline 13 & Safety from crime and other anti-social activities in the neighbourhood & $2.55(1.155)$ & $2.30(1.391)$ \\
\hline 14 & Freedom of movement within the neighbourhood environment & $4.54(1.125)$ & $3.50(0.967)$ \\
\hline 15 & Safety of lives and properties in the neighbourhood & $3.06(1.185)$ & $3.10(1.234)$ \\
\hline 16 & Safety from intra-ethnic violence & $4.26(1.056)$ & $3.03(0.926)$ \\
\hline 17 & Safety from inter-ethnic violence & $2.04(1.267)$ & $3.59(1.336)$ \\
\hline 18 & Noise level in the neighbourhood & $3.08(1,199)$ & $2.63(1.180)$ \\
\hline 19 & Level of peace within the neighbourhood & $4.05(1.273)$ & $3.02(1.397)$ \\
\hline 20 & Overall stability of the neighbourhood & $3.07(1.077)$ & $2.15(1.093)$ \\
\hline $\mathbf{M N S E S I}$ & $\mathbf{3 . 5 8}$ & $\mathbf{2 . 9 9}$ \\
\hline
\end{tabular}

HN- Homogenous neighbourhood, MN - Mixed neighbourhood, SD- Standard deviation

From the list of the first nine variables in Table 4 which relates to ethnic compositions of the neighbourhoods and their interrelationships, homogenous neighbourhoods are more satisfied, only with the exception of contact with members of other ethnic groups to which respondents expressed higher satisfaction in the mixed neighbourhoods. In the same nine attributes, mixed neighbourhoods were equally moderately satisfied with most of the attributes. This result was expected since the dominance of a particular ethnic groups in a neighbourhood 
has impact on the other items in the theme and as such reflected on their higher satisfaction. These findings are in consonance with the previous studies such as Swaroop and Krysan (2011) which reported that the White derived higher level of satisfaction in neighbourhoods with few or no members of other ethnic groups such as the Blacks and Latinos in Chicago. The finding in this research however decline in part from their report that the Blacks derive higher neighbourhood satisfaction from mixed neighbourhoods of White and Blacks. The dissonance of the findings in this regard is believed to have a link with the racial proxy hypothesis which believed that the preference of the white neighbourhoods by the blacks is due to better facilities and opportunities attributed to such neighbourhoods. The results also suggest a reflection of effect of the residents' past experience of violence which probably makes residents more comfortable residing with members of their groups; even though on the whole arrangement, they may not be fully comfortable living in a segregated environment considering their past experience of socio-cultural mix.

With regards to the quality of social activities and participation in neighbourhood social activities which also relate to liveliness of the neighbourhoods, residents in the mixed neighbourhoods expressed higher level of neighbourhood satisfaction compared to those in homogenous neighbourhoods. This result can be explained in terms of opportunities for exchange of multi-cultural ideas which are likely to be more experienced by residents in the mixed neighbourhoods than those of homogenous. Homogenous neighbourhoods on the other hand are possibly exposed to experiencing monotony and boredom interacting with the same ethnic group and monocultural dispositions. The interviewees also provided some hints on this results.

Interviewee $\mathrm{S} 2$ expressed:

... if there is no socialization, the only thing you know is you, the only culture you know is yours, the only religion you know is good is yours. You need other people, you need to understand their culture, you need to understand their religion, you need to understand their way of living. That makes you more civilized.

(Interviewee $\mathrm{S} 2$ )

On the theme of safety, residents of homogenous neighbourhoods generally appeared to believe that they do not experience much problem with these and are satisfied while residents of mixed neighbourhoods also expressed satisfaction although lower compared to those of homogenous neighbourhoods. They both expressed satisfaction with safety of their lives and property within neighbourhood but differ on satisfaction with intra and inter-ethnoreligious violence challenge. While the former were satisfied with safety from intra-ethnic violence, they were not with inter-ethnic violence. On the other hand, the latter were satisfied with both attributes. Some interviewees gave a comprehensive insight into this mixed findings.

Interviewee S4 stated:

Well, yes. Yes, because the crisis had happened and people have the notion they can no longer co-exist. So, the best thing is to actually remain segregated. Therefore, Muslims or Christians who occupy certain places tend to feel they are better off. They feel they are alone; they feel there is no one to suspect. So, the polarization [referring to segregation] tend to create sense of togetherness, sense of oneness among the people. But on the other side, I think people are more vulnerable to violence in this type of environment where an area is populated by certain groups; why, because it is very easy for non-Muslims to attack the Muslim area since they believe there are no Christians there, likewise the Muslims can easily attack the Christian neighbourhoods because they know there are no Muslim to be harmed there. But where there is a mixture, certain tendencies are likely to be. If for any reason, a Muslim planned to attack, he is likely to think twice because he understands both Muslims and Christians would be affected.

(Interviewee S4)

For the safety, it is very fluid because nobody can guarantee the safety because once anything happens to anybody in the opposite religion, it leads to spread of wrong information and crisis starts all over. So, by and large, there is sense of insecurity, there is lack of trust among neighbourhoods and that is what is in the mind of everybody in different neighbourhoods.

(Interviewee S2)

Just as I mentioned, one of the reasons for the segregation of the settlements, I mean the neighbourhoods, are issues of safety and security. Conflict has to do with perception. So, people feel more safe living in such exclusive neighbourhoods with people that share the same religion or ethnicity. If you go to places like fed lowcost or state lowcost or Rikkos, those kind of areas you still find people living side by side. In the town you may find some settlements a bit close to each other but the issue of interethnic safety is still a major issue and that's why people are still living like that.

(Interviewee S9)

Previous researchers (Aliyu et al., 2015; Ostien, 2009), who noted that as a result of the urban violence, safety became the sole determinant factor of neighbourhood choice in the study area, equally attested to the pattern of these findings. This implies that residents are currently residing in neighbourhoods where they had the feeling of safety, hence they were satisfied with it even though they may not see it as the best option for them.

However, consistent with findings of neighbourhood studies conducted in other environmental context (Hipp, 
2010; Leslie and Cerin, 2008; Mouratidis, 2017; Oslo and Urakawa, 2012; Tan, 2016b), residents in the two types of neighbourhoods were utterly dissatisfied with the rate of crime and other anti-social activities. The interviewees explained that youths gathered small arms in the period of the violence in the study area and coupled with massive destruction caused to the economy of the city thereafter, the gathered arms were used in tormenting threats on residents in different parts of the city. All the ten interviewees had a united opinion on the fact that residents are not satisfied and that the rate of crime had increased across the neighbourhoods in the city following the urban violence and the resultant segregation. They opined that proliferation of arms and criminal activities had become the order of the day.

In his opinion, Interviewee $\mathrm{S} 3$ asserted that:

As a result of the crisis, people have equipped themselves with all sorts of local and modern ammunition. So once there is no crisis, the unemployed will begin to terrorize people whether Angwanrogo, Angwanrukuba, Dadinkowa or wherever it is. These criminals move from one centre to another and certainly it has set in insecurity, what you call internal insecurity, even the communities as they are segregated. We have cases of rape, we have cases of molestation and so on and so forth. So that has been the order of the day. We hope police will do their best to make sure this rate of crime is reduced to the barest minimum.

(Interviewee S3)

Interviewee S8 also lamented:

Well, you see we don't have functional government in Africa, so nobody is safe, nobody is safe. When you are used to..., it's just like a prison, you had your freedom before but now you are in prison. Staying alone within yourselves does not give you complete satisfaction but may atimes give you depression and this aggression you transfer it to the next generation. There is a lot of crimes also. Infact it has even increased since segregation because of joblessness.

(Interviewee S8)

Regarding noise, neighbourhood peace and stability, respondents from homogenous neighbourhoods expressed satisfaction while dissatisfaction was expressed by those of mixed neighbourhoods except with the peace level where they were fairly satisfied. It appeared the respondents based their assumption of peace on their safety from ethnoreligious violence to the exclusion of the criminal anti-social activities to which they earlier expressed dissatisfaction. The result on noise was however not to be expected as residents close to the city area were expected to express lower satisfaction than those a bit away. The results suggest such other factors like noise from worship places especially churches which is equally common in the mixed neighbourhoods might have equally been put into consideration by the respondents.

3.2.3 Residents' Satisfaction with Neighbourhood Facilities and Public Utilities

Neighbourhood facilities and public utilities was the third parameter used in examining the current level of residents' satisfaction with their neighbourhoods in the segregated urban environment. On a list of fifteen (15) attributes contained in Table 5, residents in homogenous neighbourhoods were generally more satisfied with mean neighbourhood facilities and public utilities satisfaction index (MNFPUSI = 3.14) than those of mixed neighbourhoods (MNFPUSI $=2.65$ ). Notwithstanding, respondents from the mixed neighbourhoods indicated higher level of satisfaction on five (5) of the variables examined.

Table 5: Respondents' Satisfaction with the Neighbourhood Facilities and Public Services

\begin{tabular}{|l|l|l|l|}
\hline \multirow{2}{*}{ Item } & \multirow{2}{*}{ Attribute } & \multicolumn{2}{|c|}{ MAS (SD) } \\
\cline { 3 - 4 } 1 & Access recreational facilities in the neighbourhood & HN & MN \\
\hline 2 & Availability of parking facilities & $2.31(1.152)$ & $3.11(1.131)$ \\
\hline 3 & Access to public transport services & $3.50(1.057)$ & $2.26(1.199)$ \\
\hline 4 & Access to bus/car stations & $4.14(1.108)$ & $2.86(1.163)$ \\
\hline 5 & Access to public health care facilities & $2.50(1.012)$ & $2.75(1.039)$ \\
\hline 6 & Access to public library & $2.51(1.215)$ & $2.38(1.225)$ \\
\hline 7 & Availability of public toilet & $3.22(1.212)$ & $1.71(1.069)$ \\
\hline 8 & Access to public schools & $2.88(1.152)$ & $3.59(1.103)$ \\
\hline 9 & Access to police station in the neighbourhood & $2.64(1.208)$ & $2.87(1.375)$ \\
\hline 10 & Access to bank and related institutions & $3.80(1.198)$ & $2.54(1.254)$ \\
\hline 11 & Availability of worship places nearby & $3.81(1.050)$ & $3.10(1.158)$ \\
\hline 12 & Access to the nearest open air market in the neighbourhood & $3.71(1.123)$ & $1.73(1.254)$ \\
\hline 13 & Access to shopping facilities & $4.42(1.219)$ & $3.04(1.322)$ \\
\hline 14 & Public water supply in the neighbourhood & $3.23(1.218)$ & $2.69(1.265)$ \\
\hline 15 & Power supply in the neighbourhood & $2.52(1.211)$ & $2.72(1.187)$ \\
\hline MNFPSSI & $\mathbf{3 . 1 4}$ & $\mathbf{2 . 6 5}$ \\
\hline
\end{tabular}

HN- Homogenous neighbourhood, MN - Mixed neighbourhood, SD- Standard deviation 
Indication from Table 5 suggests that residents in the mixed neighbourhoods have better access to recreational and parking facilities; hence the reason why they are more satisfied. The location of most of the mixed neighbourhoods away from the centre of the city suggests a possible reason for their better satisfaction with parking, which mostly are on-street type in the study area, than the homogenous neighbourhoods. The dominance of this research's respondents in the active age range according to Table 2 provided explanations for why homogenous neighbourhoods may be less satisfied with these attributes. This was attested to by the interviewees.

Interviewee S3, S4 and S10 while responding to issues of residents' satisfaction with neighbourhood facilities in the city also observed the inadequacy of recreational facilities in the city area and emphasized its significance as a factor capable of desegregating the city in long run. In terms of satisfaction with public transport and car stations, residents in homogenous neighbourhoods expressed higher degree of satisfaction than the mixed. Locational factor of the neighbourhoods suggested a reason for this as they are generally located both within and closer to the city centre.

One of the interview respondents, Interviewee S6 mentioned library as one of the public facilities that needed to be given more attention by the government which according to him is very significant to the overall development of the state. Residents in the homogenous neighbourhoods were fairly satisfied with their access to public toilet while those of mixed were not. About $87 \%$ of the total sample of this research had children of school going age $(<$ 18 years) according to their profile provided in Table 3 . This suggested a reason why satisfaction with access to public schools was low homogenous neighbourhoods especially with the insight further provided by the interviewees. Aside, the fact that most of the residents are either low or medium income earners (Table 3) seems to be responsible for why they expected better access to public schools that can be better afforded. Residents in the mixed neighbourhoods however expressed satisfaction which the researcher believed was due more to the fact that many children in those neighbourhoods attend private schools and as such bother less about the public schools.

Interviewees explained the poor state of public facilities in the city especially in the city area when responding to the question of their opinion and view of residents' satisfaction with public facilities and public utilities. They laid serious emphasis that provided explanations for the quantitative results obtained.

Interviewee $\mathrm{S} 2$ retorted:

Ah! When you talk of this, I think the government is still yet to do anything reasonable. Let's talk about the primary health care for instance, when you go there you discover there are no workers, there are no nurses, and there is no medicine to be given to the people. Infact, it's like the whole thing is being abandoned. And the same thing with the primary schools. The infrastructure is not accessible. How then can people be satisfied with their living?

(Interviewee S2)

Interviewee S3 also opined:

In my area, I think the thing cuts across, in my area, the power we are having we task ourselves, the good schools we are having around here are private schools, not owned by the government and I believe even in the Muslim area it's like that. To me, the situation makes the government confused somehow. If we are living together if the government provides only one good school or hospital, it can serve all, both Christians and Muslims but now you have to provide a separate one for Muslims and another one for the Christians. Where are the resources? For social infrastructure no side is enjoying and cannot claim people are satisfied.

Residents from both neighbourhoods also indicated their dissatisfaction with access to police station and this suggested in part a reason why they were equally utterly dissatisfied with the rate of crime in their neighbourhoods as earlier noted.

There is a high degree of satisfaction in homogenous neighbourhoods with respect to their access to bank and availability of places of worship. The proximity of most of these neighbourhoods to the city area where these facilities were generally located suggested a reason for this expression. Respondents from mixed neighbourhoods were however not satisfied with their access to bank possibly due to their locations away. In terms of market and shopping facilities, homogenous neighbourhoods indicated a higher level of satisfaction than the mixed neighbourhood which expectedly was based on a similar explanation to that of banking services. They were both not satisfied with power and water supply to their neighbourhoods, although homogenous neighbourhood respondents expressed a fair level of satisfaction with water.

\subsection{Conclusion and Implication of the Study}

The current level of residents' satisfaction with the three main aspects of the neighbourhood environment (NPEA, NSEA and NFPU) were examined along homogenous and mixed neighbourhoods using follow-up explanatory sequential mixed method. The mean neighbourhood satisfaction index obtained across the three parameters indicated that residents from both types of neighbourhood, on a general ground, experience low degree of satisfaction with their neighbourhoods. Interviewees' opinions further explained why the residents could not be well satisfied. Variations were however recorded between the two types of neighbourhoods when examined on each of the parameters and individual variables. Residents in homogenous neighbourhoods were less satisfied with the NPEA compared to mixed neighbourhoods. Homogenous neighbourhoods have higher level of neighbourhood 
satisfaction with both NSEA and NFPU than the mixed neighbourhoods. Another area of difference is that the homogenous neighbourhoods were least satisfied with NPEA while the mixed neighbourhoods recorded the lowest satisfaction on NFPU.

The clear finding in this study however, is that residents from both types of neighbourhoods were generally more satisfied with the NSEA than either NPEA or NFPU. Opinions of the interviewees vividly supported these findings from the quantitative survey. They explained that due to the residents' experience of violence that was instrumental to the segregation of the city, the residents tend to give priority to ethnoreligious composition of their neighbourhoods and safety from inter-ethnoreligious violence. The finding was equally supported by the previous research reports. Therefore, it is pertinent that this must be given adequate consideration and top priority in any programme or policy aiming at improving neighbourhood satisfaction of residents in violence-induced segregated urban environment like Jos; be it in the homogenous areas or the mixed ones.

The revelation that NPEA are considered less important to neighbourhood satisfaction of residents in violence-induced segregated urban environment implies that residents past experience of violence has made them to give preference to safety above elements of the physical environment. This may not mean that these are not required for the wellbeing of the residents. This has therefore posed a challenge to both city planners and policy makers on the need to improve on the NPEA in order to integrate them with those of the social environment so as to have a more robust environment of living for improved quality of life of residents in the violence-induced segregated city. This is quite essential since previous studies have reported relationship between physical environment attributes and neighbourhood satisfaction and as opined by the interviewees, residents' previous experience of urban violence seems to be centrally responsible for the findings obtained in this research.

\section{References}

Adewale B.A., Taiwo, A.A, Izobo-Martins, O.O. and Ekhaeze, E.N. (2015). Age of residents and satisfaction with the neighbourhoods in Ibadan core area: A Case study of Oke Foko. Global Journal of Art Humanities \& Social Science, 3(2), 52-61.

Aliyu, A.A., Abdu, A.A., Kasim, R., \& Martin, D. (2015). Residential segregation and existing neighbourhood patterns in Jos metropolis, Nigeria. Journal of Natural Science Research, 5(16), 12-21.

Aliyu, A.A., Abdu, A.A., Kasim, R., Martin, D, Diah, M.L.M. \& Ali, H.M. (2012). Implication of intangible location attributes on residential segregation in Jos, Nigeria. Journal of Sustainable Development, 5(11), 6581.

Bartlett J.E., Kotrlik, J.W. \& Higgins, C.C. (2001). Organisational research: Determining appropriate sample size in survey research. Information Technology, Learning and Performance Journal, 1(19), 43-50.

Baruch, Y. \& Holtom, B.C. (2008). Survey response rate levels and trends in organizational research. Human Relations 61(8), 1139-1160.

Bhavanani, R., Donney, K., Miodownik, D., Mayan Mor, M., \& Helbing, D. (2014). Group segregation and urban violence. American Journal of Political Science, 58(1), 226-245.

Bischoff, K., \& Reardon, S.F. (2013). Residential segregation by income, 1970-2009. Discover America in a New Century. Russell Sage Foundation.

Buys, L., \& Miller, E. (2012). Residential satisfaction in inner urban higher-density Brisbane, Australia: role of dwelling design, neighbourhood and neighbours. Journal of Environmental Planning and Management 55(3), 319-338.

Campbell, A., Converse, P. E., \& Rodgers, W. L. (1976). The quality of American Life. New York: Russell Sage Foundation.

Chado, J. (2017). Public participation efficiency in planning for urban development in Bida, Nigeria. PhD Thesis, Faculty of Built Environment, Universiti Teknologi Malaysia.

Chapman, D. W. and Lombard, J. R. (2006). Determinants of neighbourhood satisfaction in fee-based gated and non-gated communities. Urban Affairs Review 41, 769-799.

Creswell, J. W. (2014). Research Design: Qualitative, quantitative and mixed methods approaches. Fourth Edition. SAGE Publications.

De Vita, G.E., Trillo, C. and Martinez- Perez, A. (2016). Community planning and urban design in contested places: Some insights from Belfast. Journal of Urban Design 21(3), 320-334.

Dung-Gwom, J. Y. and Rikko, L. S. (2009). Urban violence and emerging land and housing markets in Jos, Nigeria. Proceedings of the ISA Housing Conference, Glasgow, 1- 4 September 2009.

Gambo, Y. L. and Omirin, M. M. (2012). Ethno religious conflict and settlement pattern in Northern Nigeria. Mediterranean Journal of Social Sciences, 3 (3), 1-12.

Hair, J.F., Black, W.C., Babin, B.J., Anderson R.E. and Tatham, R.L. (2013). Multivariate data analysis (7 $7^{\text {th }}$ edition). Harlow: Pearson.

Hamersma, M., Taede, T. Sussman, J. and Arts, J. (2014). Residential satisfaction close to highways: The impact of accessibility, nuisances and highway adjustment projects Transportation Research Part A, 59, 106-121. 
Hipp, J. R. (2010). What is the 'neighbourhood' in neighbourhood satisfaction? Comparing the effects of structural characteristics measured at the micro-neighbourhood and tract level. Urban Studies, 47(12), 2517-2536.

Hur, H., Li, Y. and Terzano, K. (2015). Breaking the chain: Understanding the association between foreclosure intensity and neighbourhood satisfaction. Applied Geography 58, 7-17.

Ibem E.O., Opoko A.O. and Aduwo E.B. (2017). Satisfaction with Neighbourhood Environments in Public. Housing: Evidence from Ogun State, Nigeria. Soc Indic Res 130, 733-757.

Ibem, E.O. and Aduwo, E.B. (2013). Assessment of residential satisfaction in public housing in Ogun state, Nigeria. Habitat International 40, 163-175.

Jacob, R.I. (2012). A Historical Survey of Ethnic Conflict in Nigeria. Asian Social Science 8(4), 13-29.

Jagun, A., Brown, D.R., Milburn, N.G., and Gary, L.E. (1990). Residential satisfaction and socioeconomic and housing characteristics of urban black adults. Journal of Black Studies, 21(5), 719-744.

Kasara, K. (2015). Does local ethnic segregation lead to violence? Evidence from Kenya. Columbia University, an Unpublished Manuscript.

Krause, J. (2011). A deadly cycle: ethno-religious conflict in Jos, Plateau state, Nigeria. Geneva Declaration Working Paper.

Lee S.M., Conway T.L., Frank L.D., Saelens B.E., Cain K.L. and Sallis J.F. (2016). The relation of perceived and objective environment attributes to neighbourhood satisfaction. Environment and Behaviour, 1-25.

Leslie E. and Cerin, E. (2008). Are perceptions of the local environment related to neighbourhood satisfaction and mental health in adults? Preventive Medicine, 47, 273-278.

Li, Z. and Wu, F. (2013). Residential satisfaction in China's informal settlements: a case study of Beijing, Shanghai and Guangzhou. Urban Geography, 34 (7), 923-949.

Misun, H. and Hazel, M.J. (2008). Factors that influence residents' satisfaction with Neighbourhoods. Environment and Behaviour 40(5), 619-635.

Mohit, M. A., Ibrahim, M. and Rashid, Y. R. (2010) Assessment of residential satisfaction in newly designed public low-cost housing in Kuala Lumpur, Malaysia, Habitat International, 34(1), 18-27.

Mouratidis, K. (2017). Is compact city livable? The impact of compact versus sprawled neighbourhoods on neighbourhood satisfaction. Urban Studies, 1-23.

Oktay D., Rustemili, A. and Marans, R.W. (2009). Neighborhood satisfaction, sense of community and attachment: Initial findings from Famagusta quality of urban life study. ITU $A \mid Z$ 6, 16-20.

Oshio, T and Urakawa, K. (2012). Neighbourhood satisfaction, self-rated health, and psychological attributes: A multilevel analysis in Japan. Journal of Environmental Psychology 32, 410-417.

Ostien, P. (2009). Jonah Jang and the Jasawa: Ethno-Religious Conflict in Jos, Nigeria. Muslim- Christian Relations in Africa. August. <http://www.sharia-in- africa.net/media/publications/ethno-religious-conflictin-Jos-Nigeria/Ostien_Jos.pdf $>$

Parkes, A., Kearns, A., \& Atkinson, R. (2002). What makes people dissatisfied with their neighbourhoods? Urban Studies, 39(13), 2413-2438.

Permentier, M., Bolt, G., \& van Ham, M. (2011). Determinants of neighbourhood satisfaction and perception of neighbourhood reputation. Urban Studies, 48(5), 977-996.

Porio, E. (2015). Sustainable development goals and quality of life targets: insights from metro Manila. Current Sociology, 63(2), 244-260.

Rakodi, C. (2012). Inter-religious violence and its aftermath: insight from Nigerian and Indian cities. Journal of Asian and African Studies, 0(0), 1-20.

Swaroop S. and Krysan M. (2011). The determinants of neighbourhood satisfaction: racial proxy revisited. Demography, 48(3), 1203-1229.

Tan, T.H. (2016b). Neighbourhood satisfaction: responses from residents of green townships in Malaysia. International Journal of Housing Markets and Analysis, 9 (1), 137-155 